$D_{-}^{i n}$ Weltwirtschaft befindet sich nach den Ergebnissen der Gemeinschaftsdiagnose - im Frühjahr 2009 in der tiefsten Rezession seit der Großen Depression. Die Finanzkrise löste einen schweren Einbruch der Produktion aus, der auch die Schwellenländer erfasste. Die Stärke des Abschwungs im Winterhalbjahr 2008/09 erklärt sich auch daraus, dass die Produktion nahezu überall auf der Welt gleichzeitig auf Talfahrt war. Ein Ende des Einbruchs ist bislang noch nicht erkennbar, auch wenn einige Indikatoren darauf hindeuten, dass Produktion und Nachfrage in den kommenden Monaten langsamer abnehmen werden. Die Abwärtsbewegung wird wohl erst im Winterhalbjahr 2009/2010 auslaufen. Die sich anschließende konjunkturelle Belebung dürfte zunächst nur wenig Dynamik entfalten. Ein Kernproblem bleibt die anhaltende Verunsicherung an den Finanzmärkten, die vor allem auf Sorgen bezüglich der Solvenz einzelner Banken beruht und den Geldfluss zwischen den Wirtschaftsakteuren spürbar verlangsamt hat. In wichtigen Ländern kommt eine Depression am Immobilienmarkt hinzu, deren Ende noch nicht absehbar ist und die den Abschreibungsbedarf der Banken erhöht.

Insgesamt dürfte die Weltproduktion 2009 kräftig schrumpfen, die Arbeitslosigkeit dagegen massiv zunehmen. Noch dramatischer ist die Entwicklung im Welthandel, für den ein Rückgang um etwa $15 \%$ zu erwarten ist. Die deutsche Wirtschaft befindet sich in einer importierten Rezession. Da die Industrie auf Investitions- und langlebige Gebrauchsgüter spezialisiert ist, deren Nachfrage sehr konjunkturreagibel ist, hatte sie überproportional von der wirtschaftlichen Expansion bei den Handelspartnern profitiert. Nun aber ist sie in besonderem Maße betroffen, weil

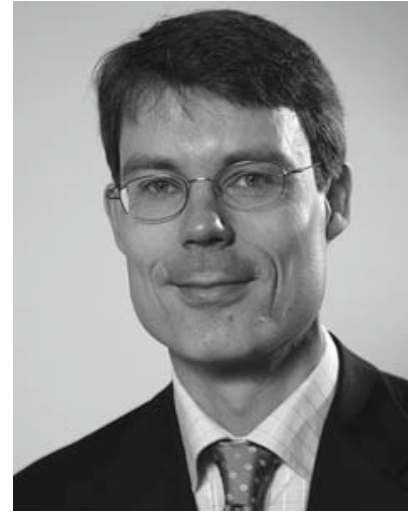

Kai Carstensen

\section{Im Sog der Weltrezession}

die Nachfrage nach diesen Waren im Zuge der Weltrezession außerordentlich zurückgeht. Mittlerweile hat sich die Krise auf die gesamte deutsche Wirtschaft ausgebreitet.

Für das 1. Quartal 2009 deuten Frühindikatoren und insbesondere die Geschäftslage, auf einen beschleunigten Rückgang der gesamtwirtschaftlichen Produktion hin. Für die kommenden Monate lassen das schwierige weltwirtschaftliche Umfeld und die vorlaufenden Indikatoren auf eine weiter rückläufige Produktionstätigkeit schließen. Zwar dürfte die Abwärtsdynamik ihren Höhepunkt überschritten haben; der Auftragsrückgang hat sich im Februar etwas verlangsamt und die ifo Geschäftserwartungen haben sich seit Dezember 2008 leicht verbessert. Dennoch bleibt die konjunkturelle Grundtendenz abwärts gerichtet.

Alles in allem wird sich das Bruttoinlandsprodukt im Jahr 2009 voraussichtlich um $6 \%$ verringern. Im Jahresverlauf dürften mehr als 1 Mio. Arbeitsplätze wegfallen. Spiegelbildlich wird die Arbeitslosigkeit hochschnellen und im Herbst die Marke von 4 Mio. überschreiten. Für 2010 ist keine durchgreifende Erholung zu erwarten. Das Bruttoinlandsprodukt dürfte um 0,5\% sinken. Zum Jahresende ist mit knapp unter 5 Mio. Arbeitslosen zu rechnen. Die Konjunkturprogramme, die wegbrechenden Steuer- und Beitragseinnahmen sowie kräftig steigende Arbeitsmarktausgaben werden die öffentlichen Budgets erheblich belasten. Für 2009 wird eine Defizitquote von $3,7 \%$ erwartet, für 2010 von 5,5\%.

Die Prognose basiert auf der Annahme, dass es zu einer, wenn auch sehr langsamen, Gesundung des internationalen Bankensystems kommt, weil die staatlichen Rettungsmaßnahmen allmählich wirken. Doch hat das globale Bankensystem weiter mit enormen Bilanzrisiken und Eigenkapitalproblemen zu kämpfen, die durch den rezessionsbedingten Anstieg der Zahl der Unternehmensinsolvenzen noch vergrößert werden dürften. Daher ist keineswegs auszuschlieBen, dass es zu einer erneuten Vertrauenskrise kommt. Die Folge könnte ein nochmaliger Einbruch bei Bestellungen und Produktion sein. Folglich ist ein Handeln der Wirtschaftspolitik weltweit dringend geboten, um die volle Funktionsfähigkeit des Bankensektors wiederherzustellen, notfalls auch durch Verstaatlichungen.

Die Europäische Zentralbank sollte den maßgeblichen Leitzins auf $0,5 \%$ senken und ihre Tendergeschäfte längerfristiger als bisher gestalten, wie sie es offenbar auch plant. Wenn ein nachhaltiger Rückgang der Kreditvolumina oder Geldmengenaggregate im Euroraum nicht anders verhindert werden kann, sollte die EZB zu einer Politik der quantitativen Lockerung übergehen, also Unternehmens- und Staatsanleihen kaufen, um eine Deflation zu vermeiden.

Kai Carstensen ist Bereichsleiter Konjunktur und Befragungen am ifo Institut für Wirtschaftsforschung in München carstensen@ifo.de

Wirtschaftsdienst $2009 \bullet 5$ 